\title{
PERSEPSI ETIKA MAHASISWA AKUNTANSI DAN AUDITOR DALAM SITUASI DILEMA ETIS AKUNTANSI
}

\author{
Rustiana \\ Universitas Atma Jaya Yogyakarta
}

\begin{abstract}
The aim of this study is to investigate about perceive differences among accounting students between auditors ethical dilemma in accounting. Two hundred and twenty eight respondents were participated in this research. Ethical perceived are measured by Multidimensional Ethics Scale with tens ethics' characteristic from 5 contructs. Ethical dilemma in accounting is measured by two hypothetical cases. Data was analysis with independent $t$-test. These results showed there are differences among accounting students between auditors. The implications of the study are to increasing content of ethic in accounting curricula.
\end{abstract}

Keywords: ethical dilemma, multidimensional ethic scale, accounting student, auditors.

\section{PENDAHULUAN}

Penelitian tentang etika dan orientasi etis dalam situasi akuntansi semakin marak dilakukan baik di luar negeri (Sweeney dan Robert,1997; Landry JR et al., 2004; Haywood et al., 2004; Radtke, 2004) maupun di Indonesia (Puspitasari, 2002; Rustiana, 2006). Penelitianpenelitian tentang etika dalam bidang akuntansi dengan responden para akuntan dan atau mahasiwa akuntansi, dipicu dengan semakin banyaknya pelanggaran etika yang terjadi di luar negeri maupun di Indonesia. Di Amerika telah terjadi skandal bisnis perusahaan besar seperti Sunbeam, Enron, Worldcom, Tyco, Health South yang melibatkan profesi akuntan dan diikuti dengan bangkrutnya KAP Arthur Andersen pada tahun 2002. Di Indonesia banyak juga terjadi pelanggaran etika yang dilakukan auditor. Dari laporan Dewan kehormatan IAI dalam Laporan Pertanggung Jawaban Pengurus IAI periode 1990 - 1994, menyebutkan adanya 21 kasus yang melibatkan 53 KAP (Ludigdo dan Machfoeds, 1999). Kemudian, pada tahun 2002 Majelis Kehormatan IAI telah memberikan sangsi terhadap 10 KAP yang melakukan pelanggaran berat saat mengaudit bank-bank yang dilikuidasi, seperti yang ditulis oleh Christiawan (2002) dengan mengutip pernyataan Winarto (2002). Kasus-kasus tersebut menyebabkan profesi akuntan publik menjadi sorotan banyak pihak. Sorotan tajam diberikan kepada akuntan publik karena profesi ini dianggap memiliki kontribusi dalam banyak kasus kebangkrutan perusahaan (IAI online, 2004). Rustiana (2006) mengutip pernyataan Khan (2002) dan Muhammad (2002), bahwa akuntan publik dihadapkan pada suatu krisis kepercayaan dan keraguan atas integritas, kredibilitas dan profesionalisme profesi, sehingga berdampak negatif terhadap profesi akuntansi (Wei, 2002 dalam Thomas 2004 ).

Kasus-kasus tersebut sebagian besar merupakan dilema etis yang sarat dengan perilaku etis yang dihadapi para pelaku bisnis, akuntan dan auditor. Integritas profesi akuntansi menjadi pertanyaan setelah adanya kasus Enron dan Arthur Anderson, sehingga menjadi kontroversi banyak pihak (Rustiana, 2006).

Pendidikan akuntansi diharapkan tetap memainkan peran utama dalam pengembangan profesional entry level employee. Rustiana (2006) mengutip pernyataan Russell dan Smith (2003) yang menyoroti bahwa kegagalan bisnis yang melibatkan salah satu kantor akuntan publik global, tidak terlepas dari desain kurikulum pendidikan tinggi akuntansi yang dirasa belum mampu 
menyediakan materi yang cukup untuk mempersiapkan mahasiswa akuntansi sebagai calon-calon akuntan dalam memasuki dunia bisnis. Clark (2003) menyatakan bahwa masyarakat dan pandangannya mempunyai pengaruh secara langsung terhadap perilaku etis. Para pendidik akuntansi dan praktisipun tidak mampu mengembangkan konsep-konsep etika yang sesuai dengan keadaan dunia bisnis yang sedang berlangsung.

Pendidikan akuntansi perlu merespon dengan melakukan perubahan desain kurikulum antara lain berupa pembahasan kasus-kasus nyata yang sedang terjadi dalam bisnis yang terkait dengan dilema etis. Pendidik akuntansi seharusnya membantu para peserta didik untuk memenuhi tantangan ini dengan membuat mahasiswa menjadi lebih siap dalam menghadapi dilema etis dalam lingkup kerja. Para mahasiswa akuntansi diperkenalkan dan dilatih agar mampu merasakan peran pentingnya etika dalam kehidupan profesional mendatang dan mampu mengembangkan perspektif kritis terhadap isu-isu etis yang sedang berkembang (Rustiana, 2006).

Pentingnya pendidikan etika dalam akuntansi telah diakui penting oleh praktisi dan akademisi. Integrasi etika ke dalam kurikulum akuntansi merupakan suatu tantangan krusial bagi pendidik akuntansi (Huss, dkk 1993). Banyak topik penelitian di bidang etika akuntansi telah dilakukan, misalnya topik identifikasi tujuan pendidikan etika dalam akuntansi (Loeb, 1988 dan 1990); masalah-masalah etika yang harus ditanggulangi (Langenderfer dan Rockness, 1989; Loeb 1988); dan kebutuhan untuk menaksir hasil pengajaran etika dalam materi akuntansi (Loeb, 1991).

Penelitian ini merupakan penelitian lanjutan dari Puspitasari (2003) dan Rustiana (2006). Puspitasari (2003) melakukan studi tentang pengaruh perbedaan gender terhadap sikap, motivasi, persepsi diskriminasi dan penilaian tingkat etika terhadap suatu tindakan dalam pekerjaan. Studi ini menggunakan responden para auditor diwilayah Solo dan Semarang. Hasilnya menunjukkan bahwa, auditor pria dan wanita menanggapi secara sama penilaian tingkat etika dengan baik terhadap beberapa contoh kasus dilema etis.

Rustiana (2006) meneliti tentang eksplorasi pembuatan keputusan etis mahasiswa akuntansi dalam situasi dilema etis akuntansi. Yang menjadi responden adalah mahasiswa akuntansi dari salah satu Perguruan Tinggi Swasta di DIY. Hasilnya menunjukkan bahwa, mahasiswa mempunyai kemampuan dalam mengenali isu-isu etika dalam situasi dilema etis secara baik.

Didasarkan pada kedua penelitian tersebut, peneliti melakukan penelitian lanjutan dengan membandingkan kemampuan mengenali isu-isu etika dalam situasi dilema etis yang diukur dengan Multidimensional Ethics Scale (MES) antara mahasiswa akuntansi dengan auditor. MES ini terdiri dari 5 konstrak moral yakni justice, relativism, deontological, utilitarism dan egoism. Alasan utama membandingkan antara kelompok mahasiswa akuntansi dengan kelompok auditor, adalah jika terdapat perbedaan nilai MES yang secara statistik signifikan, maka terjadi expectation gap antara dunia praktisi (yang diwakili oleh auditor) dan dunia akademisi (yang diwakili oleh mahasiswa akuntansi). Jika terjadi Expectation Gap, maka perlu diidentifikasi dan dicari nilai tingkat pemahaman etika yang lebih rendah berada pada kelompok mahasiswa akuntansi atau kelompok auditor. Jika nilai pemahaman tingkat pada kelompok mahasiswa akuntansi lebih rendah dari pada kelompok auditor, berarti menunjukkan pemahaman etika pada situasi dilema etis akuntansi mahasiswa akuntansi masih perlu ditingkatkan. Caranya adalah para pendidik akuntansi dapat mendesain ulang kurikulum pendidikan akuntansi dengan menambahkan materi-materi dilema etis akuntansi. Sebaliknya, jika nilai tingkat pemahaman etika auditor lebih rendah dari mahasiswa akuntansi, maka ini menjadi masukan yang serius bagi organisasi profesi (IAI) untuk memberi penekanan pada aspek etika bagi para anggotanya.

Didasarkan pada penjelasan tersebut, maka permasalahan penelitian dirumuskan sebagai berikut, apakah terdapat perbedaan persepsi etika auditor dan mahasiswa akuntansi dalam dilema etis akuntansi? Tujuan penelitian ini untuk mencari bukti empiris ada tidaknya perbedaan persepsi etis mahasiwa akuntansi dengan auditor dalam situasi dilema etis akuntansi 


\section{TINJAUAN LITERATUR}

\subsection{Definisi Etika}

Definisi etika sangat beragam, tergantung pada situasi (Cytron, 2005). Dalam beberapa konteks, etika sinonim dengan filofosi moral, yang mencoba menjawab pertanyaan teoritis mengenai sifat dan rasionalitas moral. Menurut Teori Etika Michael Davis (dikutip oleh Ashgate, 2002 dalam Cytron, 2005), etika didefinisikan sebagai

"those standards of conduct that everyone (at their rational best) wants everyone else to follow, even if that means that they have to follow too".

Dalam kasus yang lain, etika berarti kode etik khusus yang diterapkan bagi para anggota profesi tertentu. Salah satu pengertian etika menurut Mappes (1988 dalam Huss et al., 1993) adalah

Ethics can be defined as "the philosophical study of morality, and, accordingly, morality is clearly identified as the characteristic subject matter of ethics".

Dari berbagai definisi tersebut, ide utama tentang etika merupakan suatu "aturan main" tertentu yang mengatur perilaku dan seharusnya dipatuhi oleh para anggotanya.

Tujuan profesi akuntansi adalah memenuhi tanggung jawabnya dengan standar profesionalisme tertinggi, mencapai tingkat kinerja tertinggi, dengan orientasi kepada kepentingan publik. Ponemon (1988) menyatakan bahwa pertimbangan etika merupakan suatu hal yang krusial bagi status profesionalisme akuntansi yang dipercayai banyak pihak sebagai "batu penjuru" dalam praktik akuntan publik. Organisasi profesi menyediakan suatu pedoman bagi para akuntan melalui strandar profesional agar dapat membantu dalam menghadapi suatu dilema etis.

\subsection{Etika dalam Pendidikan Akuntansi}

Etika membantu komunitas bisnis dengan memfasilitasi dan mendorong kepercayaan publik dengan produk dan jasanya. Dalam profesi akuntansi, tanggung jawab secara eksplisit dinyatakan dengan berbagai kode etik seperti yang diatur oleh AICPA. Prinsip pertama kode etik ini adalah

"in carrying out their responsibilities as professionals, members should exercise sensitive professional and moral judgement in all their activities (Clark, 2003).

Alasan utama mempunyai pedoman etika bagi akuntansi adalah untuk membantu dalam proses pembuatan keputusan, tahu yang benar dan bukan hanya yang legal. Kode etik diperlukan sebagai pedoman dalam menangani situasi etis secara efektif.

Pendidikan etika bagi mahasiswa akuntansi pada tingkat minimal adalah memperkenalkan mahasiswa akuntansi dengan kode etik yang mengatur perilaku akuntan. Selanjutnya menurut Loeb (1988 dalam Huss et al., 1993) materi-materi akuntansi harus berkaitan dengan isu-isu moral. Menurutnya tujuan pendidikan etika akuntansi adalah: (a) mengkaitkan pendidikan akuntansi dengan isu-isu moral; (b) pengakuan isu-isu dalam akuntansi yang mempunyai implikasi etis; (c) mengembangkan perasaan kewajiban moral atau pertanggungjawaban; (d) mengembangkan kemampuan individu menghadapi dilema etis atau konflik etika; (e) belajar menyesuaikan dengan ketidakpastian yang dihadapi profesi akuntansi; (f) adanya perubahan dalam perilaku etika; dan (g) mengapresiasi dan memahami sejarah serta komposisi semua aspek etika akuntansi dan hubungannya dengan bidang umum etika

Bok (1976 dalam Huss et al., 1993) menyatakan bahwa ketidakmampuan individu untuk mengidentifikasi dilema etika merupakan alasan mengapa seorang individu tidak bermoral. Dengan memberikan kesempatan bagi mahasiswa untuk mendiskuskan situasi etis yang dihadapi oleh para profesional akan membuat mahasiswa menjadi lebih siap untuk mengidentifkasi keadaaan sulit terkait dengan etika. Setelah mengidentifikasi dilema etis, mahasiswa dapat 
menentukan bagaimana cara merespon dan menyelesaikannya. Penyelesaian dilema etis didasarkan pada ide-ide moral individu.

Selanjutnya Cytron (2005) menambahkan materi etika yang sebaiknya dicantumkan kedalam kurikulum akuntansi berupa: (a) sifat etika; (b) perbedaan pendekatan etika berbasis aturan vs berbasis prinsip; (c) kepatuhan dengan prinsip-prinsip fundamental etika seperti integritas, objektifitas, komitmen untuk kompetensi profesional, dan sifat kehati-hatian/due care dan kerahasiaan/confidentiality; (d) perilaku profesional dan kepatuhan dengan standar teknis dan hukum; (e) berbagai konsep seperti independensi, skeptisisme, konfik kepentingan, akuntablitas dan ekspektasi publik; (f) tanggung jawab sosial; (g) sifat tanggung jawab profesional; (h) dilema etis dan konsekuensi perilaku tidak etis terhadap individu, profesi dan sosial; dan (i) pengaturan korporasi dan kepentingan publik

Loeb (1988), Huss dan Patterson (1993) (dalam Richarson, 2004) menyatakan ada 5 tujuan yang dipertimbangkan dalam pendidikan etika akuntansi bila dikaitkan dengan independensi, yakni (1) menstimulasi imajinasi mahasiwa terhadap isu-isu independensi; (2) membantu mahasiswa dalam mengenali isu-isu independensi; (3) memperoleh rasa tanggung jawab personal dalam diri mahasiswa tentang independensi; (4) mengembangkan keahlian analitis mahasiwa agar dapat mengevaluasi isu-isu independensi; dan (5) mengajari mahasiwa supaya dapat bertoleransi dengan yang pihak yang tidak setuju dan ambiguitas independensi.

Salah satu cara untuk mengajarkan etika pada mahasiswa akuntansi adalah dengan menggunakan pendekatan modular (Mantzke et al., 2005) seperti yang telah dilakukan oleh program Master of Accounting Science di Northern Illinois University. Model ini memberikan bekal pada para mahasiswa akuntansi untuk dapat mengembangkan strategi dan membuat keputusan bisnis yang solid yang didasarkan pada akumulasi pengetahuan akuntansi dan pemahaman terhadap isu-isu bisnis yang relevan. Tujuan modul adalah (1) meningkatkan kepedulian mahasiswa terhadap standar yang mengatur profesi akuntansi, dan (2) mahasiswa mempunyai kesempatan untuk menerapkan framework dalam mengevaluasi dilema etis. Modul tersebut dapat membantu mahasiswa agar dapat mengembangkan berbagai keahlian dan kompetensi dalam hal: (a) keahlian komunikasi tertulis dengan membuat paper; (b) keahlian berkomunikasi verbal dengan teknik presentasi; (c) keahlian bernegosiasi dengan pengembangan kontrak grup; (d) keahlian mengevaluasi dengan cara mengkritisi pekerjaan yang lain; (e) keahlian berinteraksi kelompok dengan cara melakukan koordinasi berbagai tanggung jawab yang berbeda; (f) keahlian problem-solving dengan cara menentukan solusi yang dapat diterapkan; dan (g) keahlian melakukan penelitian dalam hal menemukan kode etik yang memadai untuk kasus-kasus dilema etis. Dengan demikian para mahasiswa dapat memperoleh manfaat seperti, mahasiswa menjadi lebih kaya dalam pengalaman dan dapat membuat pendekatan yang lebih relialistis jika dihadapkan pada situasi dilema etis dalam lingkungan pekerjaan.

\section{METODA PENELITIAN}

\subsection{Sampel dan Teknik Penyampelan}

Yang menjadi sampel dalam penelitian ini adalah mahasiswa akuntansi dan auditor yang bekerja di KAP. Sampel yang dipilih untuk kelompok mahasiswa adalah mahasiswa akuntansi yang sedang mengambil mata kuliah seminar akuntansi di salah satu Perguruan Tinggi Swasta di Yogyakarta. Kelompok ini dipilih dengan pertimbangan mahasiswa akuntansi yang sedang mengambil mata kuliah seminar adalah kelompok mahasiwa akuntansi yang telah memperoleh semua materi akuntansi dan dalam waktu yang relative tidak lama mereka akan siap memasuki lingkup bisnis yang sarat dengan dilema etis. Peneliti menyebarkan 180 lembar kuesioner untuk mahasiswa akuntansi. Sebanyak 177 sampel yang dapat dianalisis (respon rate 98,33\%). Sedangkan 3 buah kuesioner tidak dapat dipergunakan karena tidak lengkap. 
Kelompok kedua adalah auditor yang telah bekerja di KAP wilayah Solo dan Semarang. Data untuk kelompok ini diambil dari data yang sama dari Puspitasari (2003). Kemudian data untuk selanjutnya diolah kembali guna dibandingkan dengan kelompok mahasiswa akuntansi.

\subsection{Teknik Pengumpulan Data dan Definisi Operasional Variabel}

Data dikumpulkan dengan menyebarkan kuesioner. Kueisioner terdiri dari dua bagian yakni bagian pertama data demografi responden dan bagian kedua berisi dilema etis dengan menggunakan 2 kasus dilema etis akuntansi yang diambil dari kuesioner yang dikembangkan oleh Cohen et al. (1998) dan telah digunakan oleh Landry et al. (2004).

Dilema etis yang dimaksud adalah suatu situasi/ tindakan yang dilakukan oleh pembuat keputusan yang melibatkan adanya dilema yang terkait dengan isu etis. Dilema etis pada penelitian ini berupa dua kasus etika yang dikembangkan oleh Cohen et al. (1998) dan telah digunakan oleh Landry et al. (2004). Kasus pertama, mengenai pengakuan volume penjualan yang lebih awal oleh Manajer Penjualan sehingga dapat memperoleh bonus. Kasus kedua, mengenai Manajer Kredit yang menyetujui adanya pinjaman kredit tambahan. Padahal didasarkan pada analisis keuangan, perusahaan tersebut tidak layak untuk memperoleh kredit. Para responden diminta memberikan tanggapan atas kedua tindakan yang dilakukan para manajer pada kedua kasus dilema etis tersebut, yang didasarkan pada persepsi masing-masing. Penilaian etika diakukan dengan menggunakan Multidimensional Ethics Scale (MES) yang dikembangkan oleh Reidenbach dan Robin (1990) yang telah digunakan oleh Flory et al. (1992) dan Rustiana (2006). MES ini mengukur tingkat kesetujuan pembuatan keputusan etis dalam kasus dilema etika akuntansi. MES ini terdiri dari 5 dimensi konstrak moral yakni justice; relativism; egoism; utilitarianism; dan deontological kedalam 10 item pernyataan. Penyekalaan MES menggunakan 7 skala, yakni numerical rating scale. Skala ini untuk menunjukkan kecenderungan jawaban untuk masing-masing kelompok dimensi etis. Kelima konstrak moral tersebut adalah

1. Justice. Justice theory menyatakan bahwa sesuatu yang sama harus diperlakukan sama dan sesuatu yang berbeda harus diperlakukan berbeda. Konsep justice terdiri dari 3 karakteristik moral yakni just/tindakan yang adil, fairness/tindakan yang pantas dan morality right/secara moral dibenarkan. Angka 1 pada skala berarti karakteristik moral tindakan yang adil, tindakan yang pantas dan secara moral dibenarkan. Sedangkan angka 7 berarti karakteristik moral tindakan tidak adil, tindakan yang tidak pantas dan secara moral tidak dibenarkan. Sedangkan angka 2, 3, 4, 5 dan 6 menunjukkan kecenderungan mengarah pada angka 1 (berarti karakteristik moral cenderung tindakan adil, tindakan yang pantas dan secara moral dibenarkan) atau angka 7 (berarti karakteristk moral cenderung tindakan tidak adil, tindakan tidak pantas, dan secara moral tidak dibenarkan).

2. Relativism. Relativism theory mengasumsikan bahwa tidak ada aturan etika yang sifatnya universal yang dapat diterapkan pada setiap orang, karena keyakinan normative dipengaruhi oleh budaya dan individu itu sendiri. Konsep relativism terdiri dari 3 karakteristik moral, yakni acceptable to my family/dapat diterima oleh keluarga; culturally acceptable/secara budaya dapat diterima; dan traditionally acceptable/secara tradisional dapat diterima. Namun pada penelitian ini 2 karakteristik moral yang terkait dengan budaya dan tradisi tidak digunakan. Yang digunakan hanya karakteristik dapat diterima oleh keluarga. Angka 1 pada skala berarti diterima oleh keluarga. Sedangkan angka 7 berarti tidak diterima oleh keluarga. Sedangkan angka 2, 3, 4, 5 dan 6 menunjukkan kecenderungan menunjukkan pada angka 1 (berarti karakteristik moral cenderung diterima oleh keluarga) atau pada angka 7 (berarti karakteristik moral cenderung tidak diterima keluarga).

3. Egoism. Egoism theory menyatakan bahwa tindakan seseorang harus mendorong untuk kepentingan promosi atau kemajuan dimasa yang akan datang dalam jangka panjang. Ini menganjurkan untuk memaksimalisasi kesejahteraan individual. Konsep egoism terdiri dari 2 
karakteristik moral, yakni self-promoting for the person/promosi diri; dan personally satisfying to the person/secara personil memuaskan Angka 1 pada skala berarti karakteristik moral promosi diri, dan secara personil memuaskan Sedangkan angka 7 berarti karakteristik moral tidak promosi diri dan secara personil mengecewakan. Sedangkan angka 2, 3, 4, 5 dan 6 menunjukkan kecenderungan pada angka 1 (berarti karakteristik moral cenderung promosi diri dan secara personil memuaskan) atau pada angka 7 (berarti karakteristik moral cenderung tidak promosi diri dan secara personil mengecewakan).

4. Utilitarianism. Utilitarianism theory menyatakan bahwa setiap individu harus berupaya secara optimal untuk melakukan tindakan yang memaksimumkan manfaat dan meminimalisasi dampak negatif. Ini terdiri konstraks tindakan moral yang memaksimalkan kesejahteraan jumlah terbesar dengan biaya/cost yang minimal. Konsep utilitarianism terdiri dari 2 karakteristik moral, yakni produces the greatest utility/memperbesar utilitas; dan maximizes benefits while minimizing harm/memaksimalkan manfaat tetapi mengurangi kerusakan Angka 1 pada skala berarti karakteristik moral promosi diri, dan secara personil memuaskan Sedangkan angka 7 berarti karakteristik moral tidak promosi diri dan secara personil mengecewakan. Sedangkan angka 2, 3, 4, 5 dan 6 menunjukkan kecenderungan pada angka 1 (berarti karakteristik moral memperbesar utilitas dan memaksimalkan manfaat tetapi mengurangi kerusakan) atau pada angka 7 (berarti karakteristik moral cenderung memperkecil manfaat dan mengurangi manfaat tetapi menambah kerusakan).

5. Deontologi. Deontology theory menyatakan bahwa setiap individu memiliki kewajiban untuk memberikan kebutuhan yang menjadi hak orang lain. Sebagai contoh dalam praktik akuntan publik, merupakan suatu keharusan untuk melayani kepentingan publik. Kontraks ini mengacu pada individu yang dikaitkan dengan aspek sosial Konsep deontologi terdiri dari 2 karakteristik moral, yakni violates an unwritten contract/melanggar aturan yang tidak tertulis; dan violates an unspoken promise/melanggar kebijakan yang dianjurkan. Angka 1 pada skala berarti karakteristik moral melanggar aturan yang tidak tertulis, dan melanggar kebijakan yang dianjurkan Sedangkan angka 7 berarti karakteristik moral tidak melanggar aturan yang tidak tertulis dan tidak melanggar kebijakan yang dianjurkan. Sedangkan angka 2, 3, 4, 5 dan 6 menunjukkan kecenderungan pada angka 1 (berarti karakteristik moral cenderung melanggar aturan yang tidak tertulis dan melanggar kebijakan yang dianjurkan) atau pada angka 7 (berarti karakteristik moral cenderung tidak melanggar aturan yang tidak tertulis dan melanggar kebijakan yang dianjurkan).

\section{HASIL ANALISIS DAN PEMBAHASAN}

\subsection{Profil Responden dan Analisa Data}

Profil responden dapat dibaca pada tabel 1. Didasarkan pada tabel tersebut, dapat dibaca bahwa responden berjenis kelamin wanita sebanyak $57,46 \%$ dan responden pria $42,54 \%$. Jumlah auditor sebanyak 50 orang (atau sebesar 21,93\%) yang terdiri dari 27 responden berjenis kelamin pria dan 23 responden berjenis kelamin wanita. Sedangkan mahasiswa akuntansi berjumlah 178 (atau sebesar $78,07 \%$ ) orang dengan perincian 70 orang berjenis kelamin pria dan 108 orang berjenis kelamin wanita.

Tabel 1

Profil Responden

\begin{tabular}{lccc}
\hline Jenis kelamin & $\begin{array}{c}\text { Mahasiswa akuntansi } \\
(n=178)\end{array}$ & Auditor $(n=50)$ & Total \\
& 70 & 27 & $97(\mathbf{4 2 , 5 4 \%}$ \\
o Pria & 108 & 23 & $131(57,46 \%)$ \\
o Wanita & & & $100 \%$ \\
Total & & & \\
\hline
\end{tabular}

Sumber: Data Primer, Diolah 
Meskipun hipotesis tidak dirumuskan dalam penelitian ini, untuk menjawab ada atau tidaknya perbedaan karakteristik moral antara kelompok mahasiswa akuntansi dan kelompok auditor, digunakan alat uji independent t-test pada masing-masing kasus. Dari tabel 2 dan 3 dapat dibaca bahwa ada perbedaan signifikan antara mahasiswa akuntansi dan auditor pada beberapa karakteristik moral .

Tabel 2

Hasil Uji Beda Kasus 1

\begin{tabular}{|c|c|c|c|c|}
\hline Konstraks Moral & $\begin{array}{l}\text { Mean mhs } \\
\text { (SD) } \\
n=177\end{array}$ & $\begin{array}{c}\text { Mean } \\
\text { auditor (SD) } \\
\mathrm{N}=50\end{array}$ & \begin{tabular}{l}
\multicolumn{2}{l}{ Signifikan } \\
si \\
tailed)
\end{tabular} & Ket \\
\hline \multicolumn{5}{|l|}{ JUSTICE } \\
\hline - Just & $4,30(1,51)$ & $5,02(1,79)$ & $0,005^{*}$ & Signifikan \\
\hline - Fair & $3,93(1,71)$ & $3,10(1,83)$ & $0,003^{\star *}$ & Signifikan \\
\hline - Morality right & $4,75(1,48)$ & $4,72(1,49)$ & 0,876 & Tidak \\
\hline \multicolumn{5}{|l|}{ RELATIVISM } \\
\hline $\begin{array}{l}\text { - Acceptable to my family } \\
\text { EGOISM }\end{array}$ & EGOISM & 2,90 & $0,014^{* *}$ & Signifikan \\
\hline $\begin{array}{l}\text { - Self promoting for the } \\
\text { person }\end{array}$ & $3,02(1,56)$ & 97) & 0,097 & Tidak \\
\hline $\begin{array}{l}\text { - Personally satisfying to the } \\
\text { person } \\
\text { UTILITARIANISM }\end{array}$ & $3,34(1,78)$ & & 0,888 & Tidak \\
\hline - Produces the greatest utility & $3,69(1,46)$ & $3,98(1,91)$ & 0,248 & Tidak \\
\hline $\begin{array}{l}\text { - Maximizes benefits while } \\
\text { minimizing harm }\end{array}$ & $3,87(1,42)$ & $2,96(1,75)$ & $0,000 *$ & Signifikan \\
\hline \multicolumn{5}{|l|}{ DEONTOLOGICAL } \\
\hline $\begin{array}{l}\text { - Violates an unwritten } \\
\text { contract }\end{array}$ & & $2,86(1,63)$ & $0,022^{\star *}$ & Signifikan \\
\hline $\begin{array}{l}\text { - Violates an unspoken } \\
\text { promise }\end{array}$ & $4,63(1,74)$ & $2,82(1,59)$ & $0,000 *$ & Signifikan \\
\hline
\end{tabular}

Sumber: Data Primer, Diolah

Ket * signifikan pada $p$ value $<0,01$ (2-tailed)

** signifikan pada $\mathrm{p}$-value $<0,05$ (2-tailed)

Kasus 1

Konstraks justice.

Pengakuan volume penjualan yang lebih awal oleh manajer dalam kasus 1, dipersepsikan cenderung tidak adil/just dan tidak pantas/fair oleh mahasiwa akuntansi. Rata-rata jawaban mahasiswa akuntansi cenderung mengarah pada skala 7 (yakni 6,33 dan 5,57) lebih tinggi dibandingkan dengan rata-rata jawaban auditor yang menunjukkan nilai rata-rata 4,68 dan 3,12 dari skala 7. Rata-rata jawaban mahasiswa akuntansi yang lebih tinggi dari rata-rata jawaban auditor, diduga bahwa mahasiswa akuntansi masih memiliki persepsi pengakuan yang lebih awal mengenai volume penjualan oleh manajer tersebut, dianggap tidak sesuai dengan prinsip akuntansi berlaku umum. Sedangkan menurut sudut pandang auditor, pengakuan lebih awal volume penjualan yang dilakukan oleh manajer tersebut asalkan tidak terjadi salah saji yang material pada akun persediaan dan penjualan maka dianggap cenderung adil dan wajar/pantas. 
Konstraks relativism.

Rata-rata jawaban mahasiwa akuntansi $(3,51)$ lebih tinggi dari rata-rata jawaban auditor $(2,90)$. Ini berarti bahwa tindakan yang dilakukan oleh manajer pada kasus 1, menurut persepsi mahasiswa akuntansi cenderung lebih netral. Sedangkan auditor mempersepsikan bahwa tindakan yang dilakukan manajer tersebut cenderung dapat diterima oleh keluarga, asalkan secara keseluruhan tindakan tersebut tidak merugikan perusahaan secara material. Selain itu, pada kasus tersebut tidak tersedia informasi yang detail mengenai besarnya bonus dan besarnya volume penjualan yang harus dicatat.

Konstraks utilitarianism.

Pada konstraks ini, hanya karakteristik moral yang memaksimalkan manfaat dengan meminimalkan kerugian/kerusakan yang berbeda antara mahasiwa akuntansi dengan auditor. Rata-rata jawaban mahasiwa akuntansi sebesar 3,87 lebih tinggi dibandingkan dengan rata-rata jawaban auditor 2,96. Ini menunjukkan bahwa persepsi mahasiswa akuntansi lebih netral dibandingkan dengan auditor. Sedangkan menurut persepsi auditor, tindakan manajer pada kasus 1 sesuai dengan penerapan prinsip cost-benefit yakni memaksimalkan benefit dengan meminimalkan kerugian. Pada laporan keuangan tahunan, tindakan manajer tidak akan berdampak padabesarnya total akun penjualan ataupun akun persediaan. Kecuali apabila pengakuan yang lebih awal akun pendapatan yang dilakukan manajer tersebut, berada pada tanggal neraca, maka kemungkinan berdampak pada sifat, saat dan luasnya pengujian audit yang dilakukan auditor.

Kontraks deontological

Pada konstraks ini, terdapat perbedaan karakteristik moral. Nilai rata-rata kelompok mahasiswa akuntansi sebesar 3,42 dan 4,63 ini lebih tinggi dari jawaban rata-rata auditor sebesar 2,86 dan 2,82 masing-masing secara berurutan untuk karakteristik moral violates an unwritten contract dan violates an unspoken promise. Mahasiswa akuntansi menunjukkan persepsi yang lebih netral. Sedangkan kelompok auditor memiliki persepsi bahwa tindakan manajer tersebut cenderung melanggar aturan yang tidak tertulis dan melanggar kebijakan yang dianjurkan. Bagi auditor yang telah berpengalaman dan terlatih dalam mengaudit klien, tindakan manajer tersebut mengindikasikan kemungkinan adanya fraud yang dilakukan oleh pihak manajemen. Manajemen kurang menjalankan etika yang menjadi kewajiban moralnya sebagai pimpinan perusahaan (aspek deontologi).

Kasus 2

Tabel 3

Hasil Uji Beda Kasus 2

\begin{tabular}{|c|c|c|c|c|}
\hline Konstrak Moral & $\begin{array}{l}\text { Mean mhs } \\
(S D) n=177\end{array}$ & $\begin{array}{c}\text { Mean auditor } \\
(\mathrm{SD}) \mathrm{n}=50\end{array}$ & $\begin{array}{c}\text { Signifikansi } \\
\text { (2- tailed) }\end{array}$ & Ket. \\
\hline \multicolumn{5}{|l|}{ JUSTICE } \\
\hline Just & $6,33(0,92)$ & $4,68(1,91)$ & $0,000 *$ & Signifikan \\
\hline Fair & $5,57(1,71)$ & $3,12(1,87)$ & $0,000^{*}$ & Signifikan \\
\hline Morality right & $5,98(1,18)$ & $4,80(1,95)$ & $0,000 *$ & Signifikan \\
\hline \multicolumn{5}{|l|}{ RELATIVISM } \\
\hline $\begin{array}{l}\text { Acceptable to my family } \\
\text { EGOISM }\end{array}$ & $4,66(1,62)$ & $2,84(1,72)$ & $0,000 *$ & Signifikan \\
\hline Self promoting for the person & $3,98(1,94)$ & $3,12(1,95)$ & $0,006^{* *}$ & Signifikan \\
\hline $\begin{array}{l}\text { Personally satisfying to the } \\
\text { person }\end{array}$ & $4,55(1,96)$ & $3,50(1,76)$ & $0,001^{* *}$ & Signifikan \\
\hline
\end{tabular}




\begin{tabular}{|c|c|c|c|c|}
\hline Konstrak Moral & $\begin{array}{l}\text { Mean mhs } \\
(S D) n=177\end{array}$ & $\begin{array}{l}\text { Mean auditor } \\
(\mathrm{SD}) \mathrm{n}=50\end{array}$ & $\begin{array}{l}\text { Signifikansi } \\
\text { (2- tailed) }\end{array}$ & Ket. \\
\hline \multicolumn{5}{|l|}{ UTILITARIANISM } \\
\hline Produces the greatest utility & $4,75(1,65)$ & $4,66(1,92)$ & 0,735 & Tidak \\
\hline $\begin{array}{l}\text { Maximizes benefits while } \\
\text { minimizing harm }\end{array}$ & $4,75(1,67)$ & $2,64(1,54)$ & $0,000^{*}$ & Signifikan \\
\hline \multicolumn{5}{|l|}{ DEONTOLOGICAL } \\
\hline Violates an unwritten contract & $2,62(1,84)$ & $2,54(1,50)$ & 0,769 & Tidak \\
\hline Violates an unspoken promise & $5,87(1,33)$ & $2,44(1,43)$ & $0,000 *$ & Signifikan \\
\hline
\end{tabular}

Konstraks justice.

Ada perbedaan signifikan karakteristik moral just, fair dan morality right antara kelompok mahasiswa akuntansi dengan kelompok auditor. Rata-rata jawaban kelompok mahasiswa akuntansi secara berturut-turut sebesar 6,$33 ; 5,57$ dan 5,98. Ini lebih tinggi dari rata-rata jawaban kelompok auditor secara berurutan sebesar 4,68;3,12 dan 4,80. Mahasiswa akuntansi memiliki persepsi bahwa tindakan manajer tersebut cenderung tidak pantas, tidak adil dan secara moral tidak dibenarkan. Sedangkan kelompok auditor memiliki persepsi lebih netral atas tindakan manajer kredit tersebut. Auditor dalam mengaudit laporan keuangan klien memiliki banyak pertimbangan judgement profesional yang dapat diandalkan dalam memberikan opininya atas kewajaran laporan keuangan tersebut.

Konstraks relativism.

Untuk kontraks relativism ada perbedaan diantara kelompok mahasiswa akuntansi dan auditor. Jawaban rata-rata kelompok mahasiswa akuntansi netral $(4,66)$ dibandingkan dengan kelompok auditor sebesar 2,84. Artinya bahwa mahasiswa akuntansi memiliki persepsi bahwa tindakan manajer kredit tersebut dianggap netral. Sedangkan kelompok auditor berpersepsi secara relatif cenderung tidak berani melakukannya pada keluarganya, jika para auditor tersebut ditempatkan sebagai peran pemilik perusahaan.

Kontrask egoism.

Pada kontraks ini rata-rata jawaban kelompok mahasiwa akuntansi dengan auditor berada pada posisi netral. Namun demikian terdapat perbedaan rata-rata jawaban kelompok mahasiswa akuntansi dan auditor. Rata-rata jawaban mahasiswa akuntansi sebesar 3,98 untuk karakteristik moral self promoting for the person/menguntungkan bagi promosi si pelaku; dan sebesar 4,55 untuk karakteristik moral personally satisfying to the person/ secara personal memuaskan/ menyenangkan si pelaku. Sedangkan kolompok auditor jawaban rata-rata sebesar 3,12 untuk karakteristik moral self promoting for the person dan 3,50 untuk personally satisfying to the person. Artinya bahwa kelompok mahasiswa akuntansi cenderung berpersepsi bahwa tindakan manajer kredit tersebut menguntungkan bagi promosi si pelaku dan secara personal menyenangkan pelaku. Sedangkan pada kelompok auditor, mereka berpersepsi bahwa tindakan manajer kredit tersebut cenderung tidak menguntungkan bagi promosi si pelaku dan secara personal tidak menyenangkan bagi si pelaku.

Kontraks deontological

Pada kontraks ini terdapat perbedaan antara kelompok mahasiswa akuntansi dengan kelompok auditor hanya untuk karakteristik moral violates an unspoken promise/ melanggar kebijakan yang dianjurkan. Rata-rata jawaban kelompok mahasiswa sebesar 5,87. Ini lebih tinggi dari rata-rata 
jawaban kelompok auditor yang hanya sebesar 2,44. Artinya bahwa tindakan menajer kredit tersebut dipersepsikan ole kelompok mahasiswa akuntansi sebagai suatu tindakan yang cenderung tidak melanggar dari kebijakan yang dianjurkan. Sebaliknya,para auditorberpersepsi bahwa tindakan manjer kredit tersebut cenderung melanggar kebijakan yang dianjurkan.

\section{PENUTUP}

\subsection{Simpulan}

Penelitian ini menyediakan bukti empiris mengenai adanya perbedaan persepsi etika antara mahasiswa akuntansi dengan auditor dalam situasi dilema etis akuntansi. Situasi dilema etis akuntansi yang digunakan dalam penelitian ini ada dua kasus. Kasus pertama, manajer mengakui volume penjualan dimajukan pada bulan yang lebih awal dari yang seharusnya. dalam upaya memperoleh bonus. Sedangkan kasus ke dua berupa tindakan seorang manajer kredit yang menyetujui kredit kedua karena adanya hubungan baik dengan pemilik perusahaan, meskipun kondisi keuangan perusahaan tidak memenuhi kriteria yang ditetapkan.

Persepsi etis diukur dengan menggunakan Multidimensional Ethics Scale yang terdiri dari 5 kontraks moral yakni justice; relativism; egoism; utilitarianism, dan deontological. Perbedaan persepsi etis antara kelompok mahasiwa akuntansi dengan auditor pada kasus pertama, berasal dari kontraks moral: sebagian karakteristik moral dari justice; relativism; sebagian karakteristik moral dari utilitarianism; dan deontological. Sedangkan untuk kasus kedua, perbedaan persepsi etis kelompok mahasiswa akuntansi dan auditor berasal dari konstrak moral: justice, relativism, egoism dan sebagian karakteristik moral dari deontological,

\subsection{Keterbatasan}

Penelitian ini memiliki beberapa keterbatasan, pertama, kasus dilema etis akuntansi yang digunakan belum dapat mewakili (hanya terdiri dari dua kasus) situasi-situasi yang terkait dengan konflik etika dalam lingkungan bisnis yang kompleks. Kedua, pengukuran persepsi etis pada penelitian ini menggunakan Multidimentional Ethics Scale. Alat ini tidak mengukur tingkat alasan etis/ethical reasoning seseorang. Dalam riset-riset etika bidang akuntansi (lihat Tsui dan Windsor, 2001) biasanya menggunakan Defining Issues Tests yang dikembangkan oleh Rest (1979 dalam Sweeney dan Roberts,1997) yang bertujuan untuk mengukur alasan etis seseorang yang dinyatakan dalam P-score. Ketiga, responden mahasiswa yang dijadikan sampel hanya berasal dari salah satu perguruan tinggi swasta di Yogyakarta, sehingga hasil penelitian ini tidak dapat digeneralisasikan.

\subsection{Implikasi dan Saran}

Implikasi penelitian ada dua yakni secara teoritis dan praktis. Implikasi teoritis, pertama, menyediakan gambaran model karakteristik etika yang cukup lengkap dalam lingkungan akademisi. Kedua, membantu para pendidik akuntansi untuk semakin mencari dan menambah koleksi variasi dilema etis yang terjadi pada kondisi sebenarnya di dunia praktik, untuk diperkenalkan pada para mahasiswa akuntansi. Ketiga, membantu para pendidik akuntansi yang berminat pada bidang kajian etika, sehingga dapat mendesain materi-materi etika apa saja yang perlu diajarkan pada para mahasiswa akuntansi. Adapun implikasi praktis sebagai berikut: pertama, hasil riset ini diharapkan menambah informasi tentang perbedaan persepsi etika antara mahasiswa akuntansi dengan auditor ditinjau dari multidimensional ethics scale. Kedua, memberikan informasi penyebab perbedaan persepsi antara mahasiswa akuntansi dan auditor dari karakteristik moral pada kelima dimensi etika yakni justice, relativism, egoism, utilitarianism, dan deontological.

Saran untuk penelitian berikutnya: pertama, perlunya menambah kasus dilema etis akuntansi yang telah disesuaikan dengan kondisi di Indonesia. Kedua, alat untuk mengukur persepsi etis seseorang dapat menggunakan Defining Issue Test yang dapat mengukur alasan 
etis/ethical reasoning seseorang untuk melakukan suatu tindakan yang terkait dengan dilema etis, khususnya dalam lingkungan akuntansi. Ketiga, penelitian serupa dapat dilakukan dengan menggunakan responden auditor internal, akuntan manajemen, akuntan pemerintah ataupun akuntan pendidik.

\section{DAFTAR PUSTAKA}

Adams L., B., Malone L., F., dan James W., Jr., (1994), "Auditing: Ethical Reasoning in Confidentiality Decisions", The CPA Journal.

Allmon D., E., Page D., dan Robets R., (2000), "Determinant of Perceptions of Cheating: Ethical Orientation, Personality and Demographics". Journal of Business Ethics, Vol. 23, pp. 411422.

Ameen, J.C., D.M. Guffrey, dan J.J. Mc. Millan., (1996) "Gender Differences in Determining the Ethical Sensitivity of Future Accounting Profesionals", Journal of Business Ethics, Vol.15.

Beltramini, R., F., R. A. Peterson dan G. Kozmetsky., (1984), "Concerns of College Students Regarding Business Ethics", Journal of Business Ethic, Vol. 3.

Bertens, Kess., (2000), Pengantar Etika Bisnis, Penerbit Kanisius, Yogyakarta.

Betz, M., L. O'Connel dan J.M. Shepard., (1989), "Gender Differences in Proclivity for Unethical Behavior", Journal of Business Ethics, Vol. 8.

Borkowski, S., C., dan Ugras Y., J., (1992), "The Ethical Attitudes of Students as a Function of Age, Sex and Experience", Journal of Business Ethics, Vol.11.

Bonawitz, M.F. dan Pomeranz, F., (2002), "Analysis and Comparison of the Moral Development of Student Required to Graduate with Ethics Course", Working Paper, http://www.proquest.umi.com.didownload tanggal 15 Juni 2005.

Clark,C.K., (2003), "Reviewing the Value Ethic Education", Pennsylvania CPA Journal. Vol.74 (2), pp.18.

Christiawan, Y.J., (2002), "Kompetensi dan Independensi Akuntan Publik: Refleksi Hasil Penelitian Empiris", Jurnal Akuntansi \& Keuangan, Vol.4 (2).

Cohen, J. R., Pant, L.W., dan Sharp, D.J., (1998), "The Effect of Gender and Academic Discipline Diversity on the Ethical Evaluations, Ethical Intentions, and Ethical Orientation of Potential Public Accounting Recruits", Accounting Horizon, Vol.1 (31), pp. 250-270.

Cytron, S.H., (2005), "Evolving Curriculla: Ethics Proposal Stirs Debate", Catalyst, SeptemberOctober.

Florry, Steven M., T.J.Philips Jr., R.E. Reidenbach., dan D.P. Robin., (1992), "A Multidimensional Analysis of Selected Ethical Issues in Accounting, The Accounting Review, Vol. 67 (2), pp. 284-302.

Hass, Amy., ( 2005), "Now is the Time for Ethics in Education", The CPA Journal, Vol.75 (6). 
Haywood, M. Elizabeth., D.A. Mc Mulllen., dan D.E.Wygal., (2004), "Using Games to Enhance Student Understanding of Professional and Technical Responsibilities", Issues in Accounting Education, Vol.19 (1), pp. 85-99.

Huss, H. Fenwick, Patterson dan Denise M., (1993), "Ethics in Accounting: Values Education without Indoctrination", Journal Business Ethics.

IAI Online, (2004), "Menyoal Tanggung Jawab Profesi Akuntan Publik", Artikel di http:/www.akuntan publik.org/publikasi/pubis36.html didownload pada 26 juni 2005.

Landry, R, Jr., G. D. Moyes, dan A.C Cortes., (2004), "Ethical Perseptions Among Hispanic Student: Differences by Major and Gender", Journal of Education for Business, Vol. 80 (2).

Langenderfer, H.Q dan J.W. Rockness, (1989) Integrating Ethics into the Accounting Curriculum: Issues, Problems, and Solutions. Issues in Accounting Education.

Loeb, S.E., (1988), "Accounting Ethics: Surviving, Survival of the Fittest", Advances in Public Interest Accounting.

Loeb, S.E., (1990), "Whistleblowing and Accounting Education", Issues in Accounting Education, Vol.5., pp. 281-294.

Loeb, S.E., (1991), "The Evaluation of "Outcomes" of Accounting Ethics Educations", Journal of Business Ethics, Vol.10, pp. 77-84.

Mantzke, Katrina., G. Carnes, dan W. Tolhurst, (2005), "Incorporating Professional Ethics Throughout an Accounting Curriculum", The CPA Journal, Vol.75 (9).

Mastracchio Jr, J., ( 2005), "Teaching CPAs about Serving the Public Interest", The CPA Journal, Vol.75 (1), pp. 6-9.

Meyer, M.J dan D. McMahon, ( 2004) An Examination of Ethical Research Conduct by Experienced and Novice Accounting Academics", Issues in Accounting Education, Vol.19 (4), pp. $413-442$.

Muhammad, Marie., (2002) "Profesi Akuntan dan Kejahatan Korporasi", artikel di http://www.transparansi.or.id/berita/berita-september2002/berita_230902.html didownload tanggal 26 Juni 2005.

Puspitasari, Eka., (2003), Pengaruh Perbedaan Gender terhadap Sikap, Motivasi, Persepsi Diskriminasi dan Penilaian Tingkat Etika terhadap suatu Tindakan dalam Pekerjaan., Skripsi S1, tidak dipublkasikan.

Radtke, Robin. R. (2000), "The Effects of Gender and Setting on Accountants' Ethically Sensitive Decisions", Journal of Business Ethics, Vol.24 (4).

Richardson, R.C., (2004), "Thinking Outside of the Box (of Wine that Mis): An Exercise in Independence", Issues in Accounting Education, Vol.19 (3), pp. 363-367. 
KINERJA, Volume 10, No.2, Th. 2006: Hal. 116-128

Russell,K.A dan C.S.Smith., ( 2003), "Accounting Education's Role in Corporate Malfeasance: Its's Time for a New Currirulum", Strategic Finance, Vol. 85 (6), pp.46.

Rustiana, (2006), "Eksplorasi Pembuatan Keputusan Etis Mahasiswa Akuntansi dalam Situasi Dilema Etis Akuntansi", Modus, Vol.18 (1), pp. 49-61.

Sweeney, J.T., dan R.W. Roberts, (1997), "Cognitive Moral Development and Aucitor Independence", Accounting, Organization and Society, Vol.22 (3/4), pp. 337-352.

Thomas,C.William., (2004), "An Inventory of Support Materials for Teaching Ethics in the PostEnron Era", Issues in Accounting Education, Vol.19 (1), pp 27-52.

Tsui, J., dan C. Windsor, (2001), "Some Cross-cultural Evidence on Ethical Reasoning", Journal of Business Ethics, Vol.31 (2), pp. 173-150. 